\title{
Activity Limitation in the Elderly People and Inequalities in Brazil
}

\author{
André Luiz Barbosa de Lima*, Kenio Costa de Lima \\ Universidade Federal do Rio Grande do Norte (UFRN), Natal, Brazil \\ Email: ${ }^{*}$ andreveterinario@hotmail.com
}

Received 20 April 2014; revised 5 June 2014; accepted 15 July 2014

Copyright (C) 2014 by authors and OALib.

This work is licensed under the Creative Commons Attribution International License (CC BY). http://creativecommons.org/licenses/by/4.0/

(c) $\underset{\mathrm{EY}}{\mathrm{B}}$ Open Access

\begin{abstract}
Functional status decline in elderly individuals can compromise home life and lead to social isolation. Therefore, we aimed to determine the influence of income inequality on the limitation of activities among elderly people in Brazil. The present study included 18,484 individuals aged 60 years old or more from data of the Health Supplement of the National Household Sample Survey (PNAD), conducted in 2008. Random effects ordinal regression was proposed for multilevel analysis of the Global Activity Limitation Index (GALI), and its association among independent variables on two levels. With regards to socio-demographic status, the factors most commonly associated with activity limitation were as follows: 75 years old or more; female; living with others; living in urban areas; earning less than two minimum wages and having completed three or less years of study. With regards to health status: poor or very poor self-perceived health, hospitalization in the last 12 months, continued use of medication and depression. On a contextual level, income inequality exerted a major influence on activity limitations in elderly individuals. Analysis of these results should also consider the limitations of the data. The rural sample is not complete, because the rural north was excluded due to the logistical complexity required to conduct a survey in this area. In addition, it was not possible to use any measures of cognitive disability or mental health. We concluded that the limitations in activities among elderly individuals are reflected widely in the worsening self-rated health and condition of depression. Chronic diseases should be associated with increased activity limitations, especially chronic kidney disease, arthritis, tendinitis and cancer. The effective preventive and rehabilitation strategies for reducing the activity limitations in the elderly population should be implemented, considering the social determinants and the determinants of disability.
\end{abstract}

\section{Keywords}

Multilevel Analysis, Aged, Activities of Daily Living

Subject Areas: Geriatrics, Public Health

\footnotetext{
${ }^{*}$ Corresponding author.
} 


\section{Introduction}

The increase in life expectancy due to socioeconomic and medical progress has yielded an elderly population that is growing in size and proportion [1]. This demographical change has stimulated the studies of the health, functional ability and quality of life of elderly individuals. The increase in life expectancy of the elderly population has stimulated actions to protect functional independence in social health [2]. Functional status constitutes an important indicator of healthiness and represents a useful predictor of mortality of elderly individuals. Furthermore, it reflects the degree of an individual's independence and consequently the demand of health care services [3].

Functional status decline in elderly individuals can compromise home life and lead to social isolation. The relationship of the conceptual areas of measurement defined by several models of disability in use today provides a way extending from pathologies, impairments, functional difficulties to the disability per se. These pathologies, which may involve acute conditions or chronic problems, affect body systems and lead to impairment. The latter may involve functional limitations, in terms of limitations in physical and mental actions. These may lead to disability, which involves difficulty in doing activities in any domain of life. This process may be accelerated by personal risk factors or delayed by means of external support and interventions [4] [5].

On a contextual level, socioeconomic conditions can explain regional variations and the great diversity of the levels of health and functional disability among the elderly. Income inequality can have contextual or extraindividual effects on the social environment that affect health [5]. Brazil is a rapidly developing country with high levels of poverty and income inequality, although it has made great advances in re-organizing its healthcare system, which has become a largely government funded system, in the last two decades [6].

Studies investigating associations between the socioeconomic inequalities of the Federative Units and activity limitations in the elderly using multilevel analysis are scarce. Multilevel studies that attempt to describe ecological effects in themselves, while also including individual level effects, are now prominent in research projects about the socioeconomic determinants of health and disease.

The aim of the present study was to analyze the influence of socioeconomic factors, and health conditions on individual and contextual levels (ecological exposure effect), on the activity limitations of elderly Brazilian people.

\section{Methods}

\subsection{Data Source}

Data used in the present study are part of the Health Supplement of the National Household Sample Survey (PNAD), conducted in 2008 by the Brazilian Institute of Geography and Statistics (IBGE) and the Institute of Applied Economic Research (IPEA). These surveys collected data through home-based personal interviews and were based on a representative sample of the non-institutionalized population of Brazil. The present study included individuals aged 60 years old or more. The study sample was composed of 18,484 elderly individuals.

\subsection{Outcome Variable}

The dependent variable for the present study was based on the model proposed by Costa (2006) [7] and was called the Global Activity Limitation Index (GALI), the methodology of which is described below, considering these seven requested responses (Table 1 ).

The Global Crude Score of Activity Limitation (GCS) is calculated considering the seven requested answers jointly. Ordered category responses were assigned values, as follows: "no difficulty" -1 , "little difficulty" -2 , "great difficulty" -3 and "cannot"- 4.

The GCS value initially ranged from 7 to 26 . When the respondents answered "great difficulty" or "cannot" for the variable V1403 (Table 1), the questionnaire was interrupted and they were assigned the values 27 and 28, respectively, due to the high degree of activity limitation corresponding to such situations. Therefore, the possible values of the GCS ranged from seven to 28, corresponding to situations characterized by extreme lack of difficulty in performing any of the activities investigated and inability to care for themselves, respectively.

The following formula was used GALI $=[(28-G B S) / 21] \times 100$, where 28 the highest value and 21 the amplitude of possible values for GBS. The GALI variable was transformed into ordinal variable by dividing it into quartiles, ranging from 1 to 4 , since it is not normally distributed, where 1 is the worst condition of functionality and 4 is the best condition. 
Table 1. Questions used in the assessment of activity limitations.

\begin{tabular}{cl}
\hline Variable code & Assessment of activity limitations \\
\hline V1403 & $\begin{array}{l}\text { Usually due to health problems ... do you have difficulty feeding, bathing or going to the bathroom? } \\
\text { Usually due to health problems ... do you have difficulty running, lifting heavy objects, playing sports } \\
\text { or doing heavy work? } \\
\text { V1404 }\end{array}$ \\
$\begin{array}{l}\text { Usually due to health problems ... do you have difficulty pushing tables or performing household } \\
\text { repairs? }\end{array}$ \\
V1405 \\
V1406
\end{tabular}

Source: National Household Sample Survey (PNAD), Health Supplement 2008 (Brazil).

\subsection{Independent Variables}

The socioeconomic variables were assigned dummy values for the following reference values: gender (female), age (60 - 64 years old), race/color (others), co-residence (living with others), housing area (rural), per capita income (more than two minimum wages) and education (more than three years of study). The dummy health status variables were the following: self-perceived health (very good, good or regular) and health problems (absent back trouble, arthritis, cancer, diabetes, bronchitis/asthma, hypertension, heart disease, chronic kidney disease, depression, tuberculosis, tendinitis, cirrhosis, hospitalization in the last 12 months, continuous use of medication and health plan affiliation).

On the contextual level (27 Federative Units), two variables were assessed: the Gini coefficient of family income and the Gross Domestic Product (GDP) per capita of 2008.

\subsection{Statistical Data Analysis}

Random-effects ordinal regression model for multilevel analysis was performed by using the user-written command gllamm in Stata 12.0 (Stata Corp., College Station, TX), and fitted two-level binomial ologit link models (level 1: individuals; level 2: Federative Units).

Four multilevel models were fitted: empty model (no associated factors), model two (including the socioeconomic characteristics of individuals), model three (including the socioeconomic characteristics and health conditions of individuals) and full model (comprising all the previous individual variables on the first level and the contextual variables in the second level). The -2 log likelihood test was used to assess the quality of fit of the different models in correspondence with the theoretical plausibility.

Random intercept models were estimated and the coefficients and their standard derivations were reported, as well as the Federative Units-level (second level) variances and standard derivations, and the goodness-of-fit statistics (-2-likelihood) for each model. The confidence interval was 95\% and the significance level was 5\%.

\section{Results}

The baseline characteristics of the study population are shown in Table 2. The results showed that $14.83 \%$ experienced activity limitations while eating, bathing or going to the bathroom and $18.03 \%$ reported hospitalization in the last 12 months.

Hypertension was the most frequent chronic disease mentioned by participants (64.17\%), followed by back trouble (43.98\%), arthritis/rheumatism (35.87\%), heart disease (25.57\%) and diabetes (21.26\%) (Figure 1).

Based on these findings, the inclusion of context variables in the model did not result in significant changes in the estimates of the coefficients of the individual variables (Table 3). The probability of the elderly people exhibiting some activity limitation increased with advancing age and was higher among women.

Brown-skinned elderly people and those who lived alone were less likely to have some activity limitation. The opposite was true of those who lived in urban areas, had an income below two minimum wages and an education of less than three years.

Poor or very poor self-perceived health was related to a greater probability of having some activity limitation and was a major factor among the individual variables. Hospitalization in the last 12 months and the continued 
use of medication were significantly associated with activity limitations, followed by depression. Other problems, in order of severity, were chronic kidney disease, arthritis, tendinitis, cancer, diabetes and heart disease. Tuberculosis and cirrhosis were not significant problems in terms of activity limitations and hypertension seems demonstrate a protective effect among elderly people.

Table 2. Sample characteristics and health satisfaction of Brazilian elderly people with activity limitation, n, mean (SD), n (\%).

\begin{tabular}{lc}
\hline Variables & Total \\
\hline Number & 18,484 \\
Age (years) & 7231 (SD: 8.71) \\
Age & \\
$\quad \leq 74$ years old & $11,540(62.43)$ \\
$\quad 75+$ years old & $6944(37.57)$ \\
Sex & \\
$\quad$ Male & $6453(34.91)$ \\
$\quad$ Female & $12,031(65.09)$ \\
Race/color & \\
$\quad$ Brown (pardo) & $7192(38.91)$ \\
$\quad$ White & $9583(51.84)$ \\
$\quad$ Others & $1709(9.25)$ \\
Education & \\
$\quad \leq 3$ years & $11,137(60.25)$ \\
C3 years & $7347(39.75)$ \\
Co-residence & \\
$\quad$ Live with others & $15,895(85.99)$ \\
$\quad$ Live alone & $2589(14.01)$ \\
Perceived health & \\
$\quad$ Very good, good or regular & $13,951(75.48)$ \\
$\quad$ Poor or very poor & $4533(24.52)$ \\
\hline
\end{tabular}

Source: Health Supplement—PNAD, 2008.

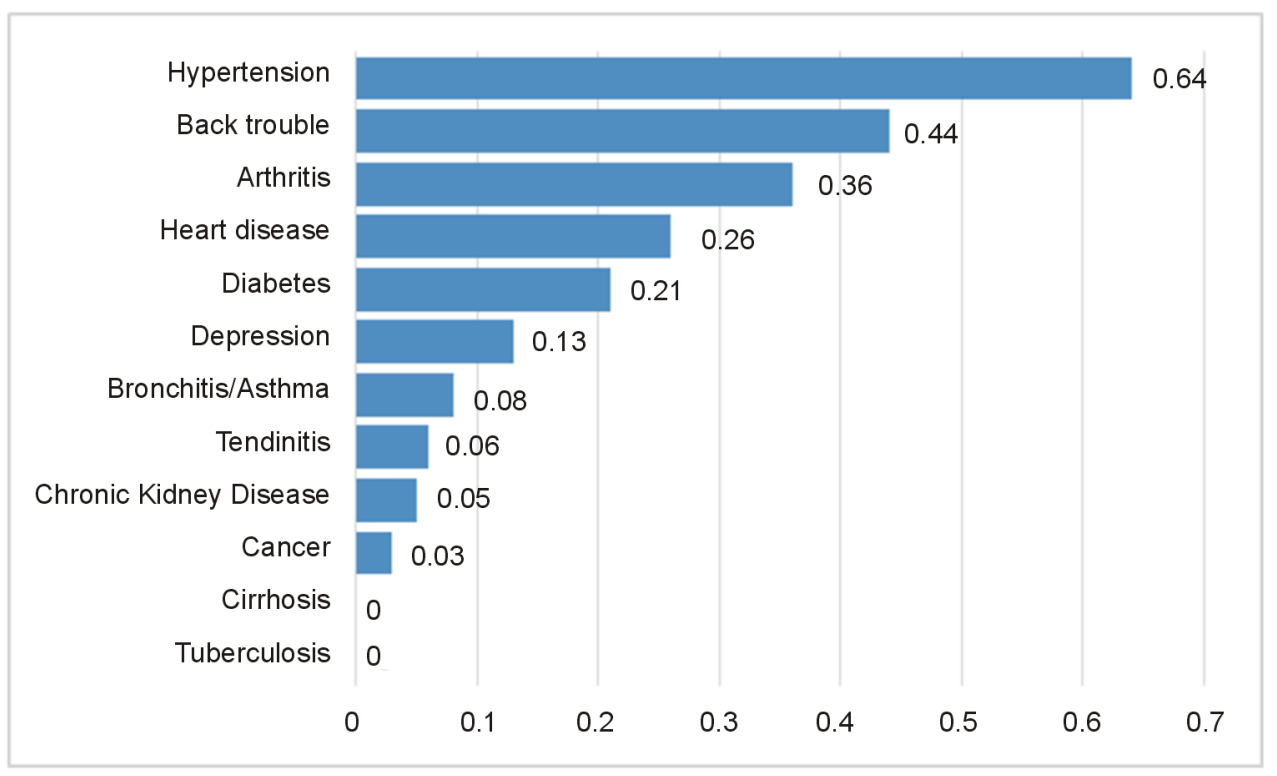

Figure 1. Proportions of chronic diseases of the elderly people with activity limitation. Source: PNAD, 2008. 
Table 3. Individual and contextual determinants of health of activity limitations in elderly people in Brazil, 2013.

\begin{tabular}{|c|c|c|c|c|}
\hline Covariates & $\begin{array}{c}\text { Model I } \\
\text { Coef. (SE) }\end{array}$ & $\begin{array}{l}\text { Model II } \\
\text { Coef. (SE) }\end{array}$ & $\begin{array}{l}\text { Model III } \\
\text { Coef. (SE) }\end{array}$ & $\begin{array}{l}\text { Model IV } \\
\text { Coef. (SE) }\end{array}$ \\
\hline \multicolumn{5}{|c|}{ LEVEL 1: individual variables: socio-demographic status ${ }^{a}$} \\
\hline \multicolumn{5}{|l|}{ Sex: (female) } \\
\hline Male & - & $0.19(0.03)^{* * *}$ & $0.25(0.03)^{* * *}$ & $0.24(0.03)^{* * *}$ \\
\hline \multicolumn{5}{|l|}{ Age group: $(60-64)$} \\
\hline $75+$ & - & $-0.89(0.03)^{* * *}$ & $-0.97(0.03)^{* * *}$ & $-0.97(0.03)^{* * *}$ \\
\hline \multicolumn{5}{|l|}{ Race/color: (others) } \\
\hline Brown (pardo) & - & $0.09(0.03)^{* *}$ & $0.07(0.03)^{*}$ & $0.08(0.03)^{*}$ \\
\hline \multicolumn{5}{|l|}{ Co-residence: (with others) } \\
\hline Alone & - & $0.17(0.04)^{* * *}$ & $0.17(0.04)^{* * *}$ & $0.17(0.04)^{* * *}$ \\
\hline \multicolumn{5}{|l|}{ Area: (rural): } \\
\hline Urban & - & $-0.16(0.04)^{* * *}$ & $-0.10(0.04)^{* *}$ & $-0.11(0.04)^{* *}$ \\
\hline \multicolumn{5}{|l|}{ Per capita income: $(>2 \mathrm{MW})^{\mathrm{b}}$} \\
\hline$\leq 2 \mathrm{MW}$ & - & $-0.25(0.04)^{* * *}$ & $-0.20(0.04)^{* * *}$ & $-0.20(0.04)^{* * *}$ \\
\hline \multicolumn{5}{|l|}{ Education: ( $>3$ years) } \\
\hline$\leq 3$ years & - & $-0.24(0.03)^{* * *}$ & $-0.17(0.03)^{* * *}$ & $-0.16(0.03)^{* * *}$ \\
\hline \multicolumn{5}{|c|}{ LEVEL 1: individual variables: health status ${ }^{a}$} \\
\hline \multicolumn{5}{|l|}{$\begin{array}{l}\text { Self-perceived health: } \\
\text { (very good, good or regular) }\end{array}$} \\
\hline Poor or very poor & - & - & $-1.18(0.03)^{* * *}$ & $-1.17(0.03)^{* * *}$ \\
\hline \multicolumn{5}{|l|}{ Back trouble: (No) } \\
\hline Yes & - & - & $-0.11(0.03)^{* * *}$ & $-0.10(0.03)^{* * *}$ \\
\hline \multicolumn{5}{|l|}{ Arthritis: (No) } \\
\hline Yes & - & - & $-0.27(0.03)^{* * * *}$ & $-0.28(0.03)^{* * * *}$ \\
\hline \multicolumn{5}{|l|}{ Cancer: (No) } \\
\hline Yes & - & - & $-0.23(0.08)^{* *}$ & $-0.24(0.08)^{* *}$ \\
\hline \multicolumn{5}{|l|}{ Diabetes: (No) } \\
\hline Yes & - & - & $-0.19(0.03)^{* * *}$ & $-0.20(0.03)^{* * *}$ \\
\hline \multicolumn{5}{|l|}{ Bronchitis/asthma: (No) } \\
\hline Yes & - & - & $0.04(0.05)$ & $0.04(0.05)$ \\
\hline \multicolumn{5}{|l|}{ Hypertension: (No) } \\
\hline Yes & - & - & $0.09(0.03)^{* *}$ & $0.10(0.03)^{* *}$ \\
\hline \multicolumn{5}{|l|}{ Heart disease: (No) } \\
\hline Yes & - & - & $-0.14(0.03)^{* * * *}$ & $-0.14(0.03)^{* * * *}$ \\
\hline \multicolumn{5}{|l|}{ Chronic kidney disease: (No) } \\
\hline Yes & - & - & $-0.33(0.07)^{* * *}$ & $-0.33(0.07)^{* * *}$ \\
\hline \multicolumn{5}{|l|}{ Depression: (No) } \\
\hline Yes & - & - & $-0.39(0.04)^{* * *}$ & $-0.40(0.04)^{* * *}$ \\
\hline \multicolumn{5}{|l|}{ Tuberculosis: (No) } \\
\hline Yes & - & - & $0.01(0.22)$ & $0.01(0.22)$ \\
\hline \multicolumn{5}{|l|}{ Tendinitis: (No) } \\
\hline Yes & - & - & $-0.26(0.06)^{* * *}$ & $-0.26(0.06)^{* * *}$ \\
\hline \multicolumn{5}{|l|}{ Cirrhosis: (No) } \\
\hline Yes & - & - & $-0.14(0.21)$ & $-0.14(0.21)$ \\
\hline
\end{tabular}




\section{Continued}

\begin{tabular}{|c|c|c|c|c|}
\hline \multicolumn{5}{|l|}{ Hospitalization in the last 12 months: (No) } \\
\hline Yes & - & - & $-0.64(0.04)^{* * *}$ & $-0.64(0.04)^{* * *}$ \\
\hline \multicolumn{5}{|l|}{ Continued use of medication: (No) } \\
\hline Yes & & & $-0.45(0.04)^{* * *}$ & $-0.45(0.04)^{* * *}$ \\
\hline \multicolumn{5}{|l|}{ Health plan affiliation: (No) } \\
\hline Yes & - & - & $0.10(0.04)^{* *}$ & $0.10(0.04)^{* *}$ \\
\hline \multicolumn{5}{|c|}{ LEVEL 2: contextual variables: inequality and income indicators in Federative Units } \\
\hline Gini coefficient-2008 & - & - & - & $-2.26(0.47)^{* * *}$ \\
\hline GDP per capita-2008 & - & - & - & $<0.001(<0.001)$ \\
\hline Intercept-cut 1 & $-1.16(0.07)^{* * *}$ & $-2.30(0.08)^{* * *}$ & $-2.30(0.08)^{* * *}$ & $-3.47(0.27)^{* * *}$ \\
\hline Intercept-cut 2 & $-0.13(0.07)$ & $-1.12(0.08)^{* * *}$ & $-1.12(0.08)^{* * *}$ & $-2.30(0.27)^{* * *}$ \\
\hline Intercept-cut 3 & $1.18(0.07)^{* * *}$ & $0.32(0.08)^{* * *}$ & $0.32(0.08)^{* * *}$ & $-0.85(0.27)^{* * *}$ \\
\hline Log likelihood & -24843.47 & -23379.71 & -23379.1 & -23371.25 \\
\hline Likelihood ratio test & - & - & $2927.51^{* * *}$ & $16.93^{* * *}$ \\
\hline Variance-Level 2-Federative Units & $<0.01$ & 0.01 & 0.01 & $<0.001$ \\
\hline Number of Level 1 units: Individuals & 18,484 & 18,484 & 18,484 & 18,484 \\
\hline Number of Level 2 units: Federative Units & 27 & 27 & 27 & 27 \\
\hline
\end{tabular}

Source: The National Household Sample Survey (PNAD) 2008; The Brazilian Institute of Geography and Statistics (IBGE) 2000; The Institute for Applied Economic Research (IPEA) 2000. ${ }^{\mathrm{a}}$ All variables are categorical data. ${ }^{*} \mathrm{p}<0.05,{ }^{* * *} \mathrm{p}<0.01,{ }^{* * *} \mathrm{p}<0.001 .{ }^{\mathrm{b}}$ Minimum wage-MW.

The full model adjusted for contextual variables, revealed a significant effect of the Gini coefficient on the GALI in Federative Units of Brazil, but not GDP per capita. Thus, elderly people living in Federative Units with greater economic inequalities were more likely to exhibit limitations of activity.

\section{Discussion}

The principal results of this study included a higher probability of activity limitations among people aged 75 years or more and among women. Many studies of self-rated health and disabilities have only focused on elderly individuals whose disability is due to aging [8]. Difficulties with physical function represented by an inability to perform normal activities of daily living, is a serious problem among the elderly [9]. Although women live longer, the quality of their final years is compromised by the difficulty in performing activities of daily living [10] [11]. It has been hypothesized that the greater prevalence and severity of arthritis and musculoskeletal diseases among elderly women explain some, but not all, of the latter difference [12]. Research examining gender differences shows that, women have greater mobility limitation than men, and may be more likely to experience mobility disability later in life than men [13]. This may be explained by possible differences in baseline physiological conditions between the genders, such as more leg extension power in men and their faster walking speed [14].

Personal sociodemographic factors, such as race and education, also contribute to functional decline. These determinants play a significant role and are potentially useful in targeting candidates for health and social services, especially if they are combined together with other precipitating events, such as acute hospital admissions or less potent illnesses and injuries [4]. The higher the level of education and income, the less likely the elderly individual will report worse functional capacity. Education provides several advantages for health because it influences behavior and psychosocial factors [5]. The adjustment of associations between skin color and health outcomes through socio-economic position indicators should be used with caution, since these indicators are part of the causal mechanism between color and outcome [15].

Elderly people living in urban areas were more likely to exhibit activity limitation. Analysis of these results should also consider the limitations of the data. The rural sample is not complete, because the rural North was excluded due the logistical complexity required to conduct a survey in this area. In addition, it was not possible to use any measures of cognitive disability or mental health. Urbanization and the aging population are some of 
the greatest challenges at the present time and will increase in coming decades [16]. Poor street conditions, heavy traffic, and low residential security are negatively associated with interpersonal interaction, obtaining health care, and voting in government elections [17]. Living in urban areas was a significant risk for functional disability in women in another study conducted in Brazil [15]. Additional studies are required, since the associations found may indicate different lifestyles of the elderly in these areas or a sub-statement of functional difficulties for rural residents.

Chronic diseases have a strong impact on activity limitations in the present study, with the exception of hypertension, which had a protective effect on elderly. Studies have indicated that the association of hypertension with disability may be mediated by the increased survival of treated hypertension patients. This hypothesis is consistent with the protective effect of hypertension on understanding and communication (i.e., cognitive functioning), which has been reported in studies of cognitive functioning and hypertension treatment [18]. The increased risk of functional limitation reflects the individual risk contributed separately by chronic diseases and depressive symptoms [19]. A number of studies have shown that morbidity coincides with the two-thirds diagnosed by health professionals. The variables most commonly associated with poorly perceived health status are chronic morbidities (hypertension, diabetes, diseases of the urinary tract, kidney failure), acute (health problem in the last month) and operating morbidities (being disabled, suffering from any physical or mental disability) [2] [20] [21].

Depression proved to be an extremely limiting factor for the functional activities of the elderly. Depression is a common and disabling disorder in later life. Epidemiological surveys indicate that $1 \%-16 \%$ of the elderly are clinically depressed. Many factors hinder the detection of depression in elderly adults. These include the presence of concurrent medical illnesses, social isolation, the insidious onset of symptoms and the occasional absence of an obvious depressed mood [22].

In the present study, elderly people who were hospitalized in the last 12 months exhibit a greater association with activity limitations. There is strong evidence of a causal relationship between disability onset and hospitalization. Hospitalized elderly individuals often develop disabilities as a consequence of staying in hospital [23].

The important protective relationship that was observed between affiliation to a health plan and activity limitations perhaps is related to indirect evidence that SUS is not the object of desire of the Brazilian middle class, and its principles counteract health insurance and omit certain compulsorily services. Health insurance provides a greater range of options (professional and services) from the point of view of users [24]. One example of the pro-rich inequality in health service utilization among those with good health status is that the wealthiest are more likely to use health services excessively, particularly those that have a private health care plan [25]. Another paradoxical effect, called the Inverse Care Law, could also affect this data. Co-morbidity and fatalism amongst the low-income strata are the major factors associated with the Inverse Care Law [26].

Aging is associated with the development of chronic disease, particularly cardiovascular, cerebrovascular and musculoskeletal conditions. The emergence and application of guidelines for the management of these conditions has resulted in an increase in the number of drugs prescribed to elderly people. The prescription of multiple medications has considerable attendant risks [27], primarily because greater disability is associated with the use of more prescription medications [12]. Age and medication use constituted predictors for disability and death in elderly people. Furthermore, medication use is associated with severe disability [1]. It is important to remember that the use of certain drugs such as sedatives, tranquillizers, antidepressants and diuretics, increases the risk of falling in elderly people [28].

Elderly individuals who live in more unequal Federative Units have a higher probability of exhibiting functional loss. The relationship between income inequality and population health has been the subject of a number of studies. The "income inequality hypothesis" contends that an individual's health is not only affected by individual income but also by the relative distribution of income in the society where the person resides [29]. The Gini coefficient and individual income were both significantly associated with declaring poor health among elderly individuals in São Paulo, Brazil. This study suggested that the elderly may be susceptible to the socioeconomic environment of residence, more specifically to the local distribution of income [30]. There is a suspicion that elderly people who live in poverty conditions might be more affected than those who are not poor. People in a precarious financial condition are more exposed to illness and death, a fact that is intensified in more vulnerable and unprotected populations, such as the elderly [31].

In the present study, our findings corroborate to conclude that women exhibit greater activity limitations than men, although they have a longer life expectancy in Brazil. Activity limitations in elderly individuals were more 
commonly associated with worse self-perceived health and depression. Chronic kidney disease, arthritis, tendinitis and cancer had negative effects on activity limitations, as did income inequalities between the Brazilian Federal Units. Further research using more direct indicators of social context is required to elucidate mechanisms through which contexts affect activity limitation in the elderly. Effective preventive and rehabilitation strategies to reduce activity limitations in the elderly should be implemented, considering the social determinants and the determinants of disability.

\section{References}

[1] Taş U., Verhagen, A.P., Bierma-Zeinstra, S.M., et al. (2007) Incidence and Risk Factors of Disability in the Elderly: The Rotterdam Study. Preventive Medicine (Baltim), 44, 272-278. http://dx.doi.org/10.1016/j.ypmed.2006.11.007

[2] Mollaoğlu, M., Tuncay, F.Ö. and Fertelli, T.K. (2010) Mobility Disability and Life Satisfaction in Elderly People. Archives of Gerontology and Geriatrics, 51, 115-119. http://dx.doi.org/10.1016/j.archger.2010.02.013

[3] Serraino, D., Fratino, L. and Zagonel, V. (2001) Prevalence of Functional Disability among Elderly Patients with Cancer. Critical Reviews in Oncology/Hematology, 39, 269-273. http://www.ncbi.nlm.nih.gov/pubmed/11500267 http://dx.doi.org/10.1016/S1040-8428(00)00130-X

[4] Nikolova, R., Demers, L., Béland, F., et al. (2011) Transitions in the Functional Status of Disabled Community-Living Older Adults over a 3-Year Follow-Up Period. Archives of Gerontology and Geriatrics, 52, 12-17. http://dx.doi.org/10.1016/j.archger.2009.11.003

[5] Alves, L.C., Leite, I.D.C. and Machado, C.J. (2010) Factors Associated with Functional Disability of Elderly in Brazil: A Multilevel Analysis. Revista de Saúde Pública, 44, 468-478. http://www.ncbi.nlm.nih.gov/pubmed/20464262 http://dx.doi.org/10.1590/S0034-89102010005000009

[6] Channon, A.A., Andrade, M.V., Noronha, K., et al. (2012) Inpatient Care of the Elderly in Brazil and India: Assessing Social Inequalities. Social Science \& Medicine, 75, 2394-2402. http://dx.doi.org/10.1016/j.socscimed.2012.09.015

[7] Costa, A.J.L. (2006) Metodologias e indicadores para avaliação da capacidade funcional: Análise preliminar do Suplemento Saúde da Pesquisa Nacional por Amostra de Domicílios PNAD, Brasil, 2003. Ciência \& Saúde Coletiva, 11, 927-940. http://dx.doi.org/10.1590/S1413-81232006000400015

[8] Bodde, A.E., Seo, D.-C. and Frey, G. (2009) Correlation between Physical Activity and Self-Rated Health Status of Non-Elderly Adults with Disabilities. Preventive Medicine (Baltim), 49, 511-524. http://dx.doi.org/10.1016/j.ypmed.2009.10.004

[9] Beckett, L.A., Brock, D.B., Lemke, J.H., et al. (1996) Analysis of Change in Self-Reported Physical Function among Older Persons in Four Population Studies. American Journal of Epidemiology, 143, 766-778.

http://www.ncbi.nlm.nih.gov/pubmed/8610686 http://dx.doi.org/10.1093/oxfordjournals.aje.a008814

[10] Castro, M., Camargos, S., Helena, I., et al. (2005) Expectativa de vida com incapacidade funcional em idosos em São Paulo, Brasil. Revista Panamericana de Salud Pública, 17, 379-386. http://dx.doi.org/10.1590/S1020-49892005000500010

[11] Leveille, S.G., Penninx, B.W., Melzer, D., Izmirlian, G. and Guralnik, J.M. (2000) Sex Differences in the Prevalence of Mobility Disability in Old Age: The Dynamics of Incidence, Recovery, and Mortality. The Journals of Gerontology: Series B, 55, S41-S50. http://www.ncbi.nlm.nih.gov/pubmed/10728129 http://dx.doi.org/10.1093/geronb/55.1.S41

[12] Murtagh, K.N. and Hubert, H.B. (2004) Gender Differences in Physical Disability among an Elderly Cohort. American Journal of Public Health, 94, 1406-1411.

http://www.pubmedcentral.nih.gov/articlerender.fcgi?artid=1448463\&tool=pmcentrez\&rendertype=abstract http://dx.doi.org/10.2105/AJPH.94.8.1406

[13] Yeom, H.A., Fleury, J. and Keller, C. (2008) Risk Factors for Mobility Limitation in Community-Dwelling Older Adults: A Social Ecological Perspective. Geriatric Nursing, 29, 133-140. http://dx.doi.org/10.1016/j.gerinurse.2007.07.002

[14] Rantanen, T. and Avela, J. (1997) Leg Extension Power and Walking Speed in Very Old People Living Independently. The Journals of Gerontology: Series A, 52, M225-M231. http://www.ncbi.nlm.nih.gov/pubmed/9224434 http://dx.doi.org/10.1093/gerona/52A.4.M225

[15] Parahyba, M.I., Veras, R. and Melzer, D. (2005) Incapacidade funcional entre as mulheres idosas no Brasil. Revista de Saúde Pública, 39, 383-391. http://dx.doi.org/10.1590/S0034-89102005000300008

[16] Sundsli, K., Espnes, G.A. and Söderhamn, O. (2013) Lived Experiences of Self-Care among Older Physically Active Urban-Living Individuals. Clinical Interventions in Aging, 8, 123-130. http://dx.doi.org/10.2147/CIA.S39689 
[17] Clarke, P.J., Ailshire, J.A., Nieuwenhuijsen, E.R. and Vrankrijker, M.W. (2011) Participation among Adults with Disability: The Role of the Urban Environment. Social Science \& Medicine, 72, 1674-1684.

[18] Virués-Ortega, J., de Pedro-Cuesta, J., del Barrio, J.L., Almazan-Isla, J., Bergareche, A., Bermejo-Pareja, F., et al. (2011) Medical, Environmental and Personal Factors of Disability in the Elderly in Spain: A Screening Survey Based on the International Classification of Functioning. Gaceta Sanitaria, 25, 29-38.

[19] Hairi, N.N., Bulgiba, A., Mudla, I. and Said, M.A. (2011) Chronic Diseases, Depressive Symptoms and Functional Limitation amongst Older People in Rural Malaysia, a Middle Income Developing Country. Preventive Medicine, 53, 343-346. http://dx.doi.org/10.1016/j.ypmed.2011.07.020

[20] Gallegos-Carrillo, K., García-Peña, C., Duran-Muñoz, C., Reyes, H. and Durán-Arenas, L. (2006) Autopercepción del estado de salud: Una aproximación al los ancianos en México. Revista de Saúde Pública, 40, 792-801. http://dx.doi.org/10.1590/S0034-89102006000600008

[21] Alexandre, T.D.S., Corona, L.P., Nunes, D.P., Santos, J.L.F., Duarte, Y.A.O. and Lebrão, M.L. (2012) Gender Differences in Incidence and Determinants of Disability in Activities of Daily Living among Elderly Individuals: SABE Study. Archives of Gerontology and Geriatrics, 55, 431-437. http://dx.doi.org/10.1016/j.archger.2012.04.001

[22] Almeida, O.P. and Almeida, S. (1999) Short Versions of the Geriatric Depression Scale: A Study of Their Validity for the Diagnosis of a Major Depressive Episode According to ICD-10 and DSM-IV. International Journal of Geriatric Psychiatry, 14, 858-865. http://www.ncbi.nlm.nih.gov/pubmed/10521885

[23] Wu, C.Y., Hu, H.Y., Li, C.P., Fang, Y.T., Huang, N. and Chou, Y.J. (2013) The Association between Functional Disability and Acute Care Utilization among the Elderly in Taiwan. Archives of Gerontology and Geriatrics, 57, 177-183. http://dx.doi.org/10.1016/j.archger.2013.04.011

[24] Elias, P.E.M. and Cohn, A. (2003) Health Reform in Brazil: Lessons to Consider. American Journal of Public Health, 93, 44-48. http://www.pubmedcentral.nih.gov/articlerender.fcgi?artid=1447689\&tool=pmcentrez\&rendertype=abstract http://dx.doi.org/10.2105/AJPH.93.1.44

[25] Szwarcwald, C.L., Souza-Júnior, P.R.B. and Damacena, G.N. (2010) Socioeconomic Inequalities in the Use of Outpatient Services in Brazil According to Health Care Need: Evidence from the World Health Survey. BMC Health Services Research, 10, 217. http://dx.doi.org/10.1186/1472-6963-10-217

[26] Petti, S. and Polimeni, A. (2011) Inverse Care Law. British Dental Journal, 210, 343.

[27] Hubbard, R.E., O’Mahony, M.S. and Woodhouse, K.W. (2013) Medication Prescribing in Frail Older People. European Journal of Clinical Pharmacology, 69, 319-326. http://dx.doi.org/10.1007/s00228-012-1387-2

[28] Jäntti, P.O., Pyykkö, V.I. and Laippala, P. (1993) Falls among Elderly Nursing Home Residents. Public Health, 107, 89-96. http://www.ncbi.nlm.nih.gov/pubmed/7599243

[29] Feng, Z., Wang, W.W., Jones, K. and Li, Y. (2012) An Exploratory Multilevel Analysis of Income, Income Inequality and Self-Rated Health of the Elderly in China. Social Science \& Medicine, 75, 2481-2492. http://dx.doi.org/10.1016/j.socscimed.2012.09.028

[30] Filho, A.D.P.C., Lebrão, M.L. and Kawachi, I. (2012) Income Inequality and Elderly Self-Rated Health in São Paulo, Brazil. Annals of Epidemiology, 22, 863-867. http://dx.doi.org/10.1016/j.annepidem.2012.09.009

[31] dos Santos, A.A. and Pavarini, S.C.I. (2011) Functionality of Elderly People with Cognitive Impairments in Different Contexts of Social Vulnerability. Acta Paulista de Enfermagem, 24, 520-526. 